\title{
Erratum
}

\section{Disproportionation of Enantiomers by Precipitation}

\section{W. THIEMANN}

J.Mol.Evoi. 4, 85-97 (1974)

Received February 24, 1975

Due to a mistaken specific rotation all the figures of the last column in table 1, p.91, are unfortunately wrong and must be replaced by the new figures as given.

Table 1. Summary of Results of Precipitation from Racemic Conditions ${ }^{a}$

\begin{tabular}{|c|c|c|c|c|c|}
\hline $\mathrm{C}_{0}[\mathrm{Mol} / 1]$ & $\mathrm{T}\left[{ }^{\circ} \mathrm{C}\right]$ & $M_{0} / M_{p}$ & $\mathrm{C}_{\mathrm{p}}[\mathrm{MOl} / 1]$ & $\alpha\left[\mathrm{m}^{\circ}\right]$ & $\left(\mathrm{c}_{\mathrm{L}} / \mathrm{c}_{\mathrm{D}}\right)_{\mathrm{p}}$ \\
\hline 0.191 & 0 & 12.3 & 0.265 & 10.0 & 0.988 \\
\hline 0.218 & o & 4.3 & 0.340 & $-\quad 59.0$ & 0.947 \\
\hline 0.191 & o & 13.5 & 0.238 & -8.3 & 0.989 \\
\hline 0.291 & o & 1.2 & 0.700 & -0.8 & 0.999 \\
\hline 0.249 & 0 & 2.2 & 0.367 & $-\quad 12.6$ & 0.989 \\
\hline 0.297 & o & 1.7 & 0.732 & 1.3 & 0.999 \\
\hline 0.297 & 5 & 2.2 & 0.626 & $-\quad 10.1$ & 0.995 \\
\hline 0.254 & 7.5 & 4.5 & 0.343 & 3.0 & 0.997 \\
\hline 0.191 & 7.5 & 475.6 & 0.006 & 2.1 & 0.896 \\
\hline 0.349 & 7.5 & 1.7 & 1.011 & 5.6 & 0.998 \\
\hline 0.349 & 7.5 & 1.6 & 0.499 & 5.6 & 1.003 \\
\hline 0.292 & 7.5 & 2.2 & 0.614 & 4.3 & 0.998 \\
\hline 0.311 & 8 & 2.4 & 0.443 & $+\quad 78.7$ & 1.057 \\
\hline 0.291 & 8 & 2.8 & 0.575 & 2.4 & 1.001 \\
\hline 0.349 & 8 & 1.6 & 1.074 & $+\quad 11.1$ & 1.003 \\
\hline 0.299 & 8.5 & 1.2 & 0.639 & +153.0 & 1.078 \\
\hline 0.249 & 8.5 & 2.2 & 0.438 & +15.2 & 1.011 \\
\hline 0.267 & 8.5 & 3.8 & 0.380 & +29.0 & 1.024 \\
\hline 0.254 & 9 & 31.0 & 0.089 & $-\quad 55.6$ & 0.822 \\
\hline 0.272 & 9 & 12.8 & 0.272 & 22.1 & 0.975 \\
\hline 0.249 & 9 & 3.4 & 0.557 & 13.2 & 1.007 \\
\hline 0.299 & 9 & 2.0 & 0.706 & 9.4 & 1.004 \\
\hline 0.297 & 9 & 2.6 & 0.576 & 6.4 & 1.003 \\
\hline 0.272 & 10 & 197.7 & 0.018 & +0.4 & 1.007 \\
\hline 0.299 & 12.5 & 2.5 & 0.558 & +14.8 & 1.008 \\
\hline 0.374 & 12.5 & 1.6 & 0.885 & 16.8 & 1.006 \\
\hline
\end{tabular}

axplanation of abreviations in the text 
The ratio $\left(c_{L} / c_{D}\right) p$ is calculated in the following way (notation as previously given in the article):

$$
\begin{aligned}
& c_{p L}=\left(c_{p}+\frac{\alpha}{[\alpha]}\right) \cdot \frac{1}{2} \\
& c_{p D}=c_{p}-c_{p L}
\end{aligned}
$$

whence

$$
\left(\frac{C_{L}}{C_{D}}\right)_{p}=\frac{\left(C_{p}+\frac{\alpha}{[\alpha]}\right)}{2\left(C_{p}-C_{p L}\right)}
$$

The error was caused by the fact that the specific angle of rotation at $250 \mathrm{~nm}$ and $\mathrm{pH}=1,25$ was taken in the calculation by a factor 10 too small. The correct value for $[\alpha]]_{250 \mathrm{~nm}}^{22,5^{\circ}}$ at $\mathrm{pH}=1,25$ for asparagine is +426 .

Fortunately the revised values indicate considerably smaller enrichments of the enantiomers as previously given without changing the qualitative interpretation! - which would be consistent with the hypothesis of the small asymmetry effects.

Dr.Wolfram Thiemann, Institut für Physikalische Chemie, Kernforschungsanlage Jülich $\mathrm{GmbH}$, D-5170 Jülich, Postfach 365, Federal Republic of Germany 